\title{
O lugar de POSIÇÃo de CAMÕes na galáxia literária doS PAÍSES LUSÓFONOS
}

\author{
Manuel Ferro* \\ ferro@fl.uc.pt
}

\begin{abstract}
RESUMO: Na galáxia das literaturas de língua portuguesa, expressão da cultura dos países falantes do luso idioma, sem dúvida alguma que Camões representa uma referência a seguir e a tomar em conta não só no contexto português, como também no das restantes nações. Pelo facto, e a título de exemplo, é analisado o modo como o Canto V de Os Lusíadas vem a ser aproveitado como fonte de inspiração e ponto de partida por um dos autores angolanos contemporâneo, Pepetela para a composição do conto intitulado "Estranhos pássaros de asas abertas", depois inserido no volume Contos de Morte. Apontam-se as mudanças de perspetiva, a valorização do contexto cultural nativo, evidenciando-se a estranheza daqueles seres que aparecem provenientes de longínquas paragens, mais parecidos com espíritos do que com criaturas de condição humana. Numa abordagem pós-moderna, a visão pós-colonial dominante adequa-se, pois, a uma revisitação do passado, da tradição literária e da obra maior da portugalidade à luz de novos parâmetros.
\end{abstract}

PALAVRAS-CHAVE: Luís de Camões, Os Lusíadas, Pepetela, Contos de Morte, Pós-Modernismo, Estudos Pós-Coloniais, Tradição literária.

Se José Augusto Seabra, em 1998, fala das “aventuras de uma língua em expansão galáctica, [...] num horizonte de universalidade de que há-de renascer sempre” (SEABRA, 1998, p.13), mostrando como o devir da língua portuguesa, seguindo uma perspectiva diacrónica, a transformou na "pátria de várias pátrias", sob o signo da unidade na diversidade, o certo é que ela se materializou igualmente em sete literaturas, oito se lhe juntarmos a goesa, que são a sua expressão máxima de arte e identidade. Permanecendo a mesma e simultaneamente outra, graças à sua capacidade regeneradora, defende ainda J. A. Seabra que "a vocação da nossa língua foi sempre a de incorporar na sua cepa fundadora elementos civilizacionais diversos, [...] em espaços geoculturais múltiplos, que hoje correspondem aos dos sete países independentes, prolongando-se ainda numa larga diáspora disseminada um pouco por todo o mundo" (SEABRA, 1998, p.8).

\footnotetext{
* Doutor em História. Universidade de Coimbra. Centro Interuniversitário de Estudos Camonianos.
} 
E se, por um lado, António Ferreira na carta a Pero de Andrade Caminha, em louvor da língua portuguesa, o exorte ao seu uso e à ilustração do idioma pátrio, dizendo,

Floresça, fale, cante, ouça-se e viva

A portuguesa língua, e, lá onde for,

Senhora vá de si, soberba e altiva. (FERREIRA, 2000, 263)

defende igualmente nessa composição, e em tom acalorado, as virtualidades e as potencialidades expressivas da língua materna, atribuindo-lhe a capacidade de primorosa expressão do sentimento da nacionalidade, deste modo se entendendo a portugalidade do seu tempo (MARQUES, 1973, p.28). E sobre este excerto, comenta J. Augusto Seabra:

Lá onde for"... A "portuguesa língua" iria, na verdade, do Norte ao Sul e do Ocidente ao Oriente, através dos oceanos - do Atlântico ao Índico, do Índico ao Pacífico -, deixando por terras de África, da América e da Ásia as suas sementes, que foram florescendo em falares e cantos com sonoridades diversas, fossem elas as dos crioulos e dos papiás, sem que jamais deixasse de ser "senhora" de si mesma, na sua dignidade e na sua identidade essencial. (SEABRA, 1973, p.10).

Em paralelo, se se fixa através de obras de referência, atingindo a sua maioridade, permite que, simultaneamente, se inicie um processo de sistematização mediante a elaboração de gramáticas. Foi com o poema de Camões que alcançou esse estatuto, num contexto em que outros escritores, porém, haviam reconhecido o grau de elaboração atingido dentro da linha de evolução que a língua tinha vindo a sofrer:

O momento - e o monumento - que constitui o apogeu da língua portuguesa é, no entanto, entre todos, o da publicação d'Os Lusíadas, em 1572. Não só Camões dotou Portugal da sua Epopeia, em que a Pátria veio a reconhecer-se, mas explorou de forma multímoda as virtualidades expressivas do idioma. [...] Não foi em vão, na verdade, que se passou a partir daí a falar correntemente da "língua de Camões" (SEABRA, 1973, p.10).

A partir de então, nesse processo de expansão linguístico-cultural, o enriquecimento a que se submete, vem dotá-la de uma plasticidade e capacidade de adaptação aos mais variados climas, ambientes culturais e realidades, fazendo dela sempre a mesma, mas múltipla na sua variada e rica expressão de referentes diversificados. 
A «mestiçagem antropológica e cultural é outrossim um elo de ligação comum aos outros espaços civilizacionais lusófonos, que viriam mais, a exemplo do Brasil - embora tendo passado pela prova de fogo trágica de uma guerra colonial - a conquistar a independência, constituindo novos espaços da expansão da galáxia lusófona» (SEABRA, 1973, p.13).

Por outro lado, se depois se assiste à diferenciação gradual das literaturas dos países africanos, tal facto tem como fundamento os contextos, as vivências, a sensibilidade e as tradições culturais que lhes são inerentes (Cf. SEABRA, 13). Nalguns casos específicos, insiste-se na valorização da negritude como forma de afirmação de uma identidade civilizacional face ao colonizador, muito embora a assunção da língua portuguesa ocorra e se verifique a capacidade plástica de incorporação no seu substrato de valores e elementos nativos (Cf. SEABRA,1973,p.13). A apropriação da língua portuguesa impõe-se, então, adotada sem dramas e conflitos, nem traumas, como uma forma de expressão da sua identidade na alteridade, sem colidir com o uso das línguas nativas, de cuja cultura passa a ser a sua expressão primeira.

Ora num contexto de pós-modernidade, em que a revisitação, recuperação e revitalização da grande tradição literária do passado tem lugar, projeta-se uma visão perspetivada de novos ângulos, mais adequados a uma mundivisão atual das questões e situações outrora abordadas, mas que preservam a sua pertinência mesmo num contexto diferenciado e num mundo em constante transformação. Não é por acaso que Linda Hutcheon dedica particular atenção a este diálogo produtivo que acaba por ter lugar sobremaneira no âmbito da criação literária:

Não é um retorno nostálgico; é uma reavaliação crítica, um diálogo irônico com o passado da arte e da sociedade, a ressurreição de um vocabulário de formas arquitetônicas criticamente compartilhado. [...] $\mathrm{Na}$ maior parte dos trabalhos de crítica sobre o pós-modernismo, é a narrativa - seja na literatura, na história ou na teoria - que tem constituído o principal foco de atenção. A metafísica historiográfica incorpora todos esses três domínios, ou seja, sua autoconsciência teórica sobre a história e a ficção como criações humanas (metaficção historiográfica) passa a ser a base para seu repensar e sua reelaboração das formas do conteúdo do passado. (HUTCHEON, 1991, p.22 e 24-25)

Através dessa reavaliação crítica, traduzida na associação de representações reais ou imaginárias, colhidas de obras literárias de referência do passado, traduz-se uma das múltiplas fórmulas do pós-modernismo, onde o gosto pela reescrita permite o despoletar da fantasia, da liberdade criativa, da paródia ou de outras estratégias, que 
depois acabam por plasmar de forma mais objetiva as características da contemporaneidade literária e imprime um cunho de vitalidade à prossecução da tradição que é, por sua vez, um traço da identidade de uma cultura. Não será por acaso que, na Poética do Pós-Modernismo, Linda Hutcheon ainda refira:

[...] As representações do passado são selecionadas para significar tudo o que o historiador pretende. É essa mesma diferença entre acontecimentos (que não têm sentido em si mesmos) e fatos (que recebem um sentido) que o pós-modernismo enfatiza obsessivamente. [...] O que os discursos pós-modernos - fictícios e historiográficos perguntam é: como conhecemos e entramos em acordo com uma "coisa" tão complexa? (HUTCHEON, 1991, 162)

A complexidade de análise inerente ao Pós-Modernismo advêm, por conseguinte, da vitalidade do próprio movimento que, gradualmente, se foi enriquecendo e elaborando, numa hábil estratégia, através da qual se assiste à recuperação tanto de acontecimentos passados, quanto contemporâneos, que marcaram e vão marcando (e por vezes manchando) o percurso da História (FRANCISCO, 2011, p.39-40).

Neste sentido, assume-se a capacidade regeneradora da tradição, que, apoiada numa perspetiva crítica e teórica, constantemente reformulada, reflete sobre a configuração e a recomposição de imagens do mundo contemporâneo, bem como sobre as relações que constantemente se transformam e adquirem novos contornos. Neste contexto, o cânone impõe a sua pertinência por resultar e simultaneamente configurar a tradição, arvorando-se em produtivo sustentáculo de inúmeras formas de receção, porventura igualmente originais, ou também menos bem-sucedidas, secundárias, que atestam a vitalidade dos modelos seguidos. Em qualquer dos casos, e na sequência do exposto por José Augusto Seabra, a (re)apropriação e expropriação temáticas nas literaturas lusófonas, favorece, pois, a discussão para uma redefinição dos conceitos de contínuo tomados e, em paralelo, a afirmação de identidades no contexto de novas forças políticas, socioeconômicas e culturais. Por conseguinte, a situação da lusofonia na contemporaneidade favorece a reflexão e a abordagem de aspetos, fenómenos e questões intrinsecamente articulados com a memória cultural e literária, muito embora as mudanças significativas ocorridas, em especial no último quartel do século XX e nestes breves anos do século XXI, no âmbito político-social e económico, desde a independência dos países lusófonos à agudização da crise a nível internacional, 
acarretem um reflexo negativo consequente sobre a produção artística e literária. Por isso, os pressupostos que sustentam a tendência dos estudos pós-coloniais dentro da era pós-moderna proporcionam preciosos instrumentos e estratégias de abordagem, na medida em que, além de permitirem a revisão e a consequente questionação do enfoque 'oficial' dos acontecimentos e do processo histórico durante o período colonial, imperialista e neocolonial, facilitam a compreensão do percurso seguido na construção dos novos Estados e sua identidade, evidenciando aspetos como o sistema de valores, conceitos e preconceitos das sociedades em causa, o modo de se relacionarem com outras comunidades, num mundo globalizado e cosmopolita, muito embora preservando traços que a memória e a tradição consagram, expressos através da oralidade, do folclore, do mito e da própria História, agora abordados segundo modelos em que a desconstrução e a fuga ao cânone abrem novas perspetivas e redescobrem novos sentidos (NAYAR, 2008).

Neste contexto, contudo, um fenómeno há a registar que envolve o mercado das letras, muito particularmente no que diz respeito às edições de Os Lusíadas. Recordando e pondo em paralelo a conjuntura atual com o contexto de crise política do início do século XVII, quando Portugal se encontrava sob o domínio filipino e a figura do Poeta, bem como o seu poema se arvoram em símbolos da cultura de um povo e alimentam as tendências nacionalistas que acabam por sair bem-sucedidas na manhã do primeiro de Dezembro de 1640, de modo semelhante, na atualidade, Os Lusíadas continuam a ser uma referência constante não só na cultura e literatura portuguesa como também, como veremos, em todo o mundo lusófono.

Não há muito tempo que o Jornal Expresso tomou a iniciativa de editar algumas obras de referência do período de ouro das letras portuguesas, da época em que a expansão lusa pelos restantes continentes tinha igualmente tido lugar. Os méritos da edição de Os Lusíadas (CAMÕES, 2003), se outros não houvesse, recaem em duas vertentes. Tal como no primeiro quartel do século XVII, Manuel Correia e Manuel Severim de Faria se aperceberam da ignorância generalizada sobre a figura tutelar de Camões e a dificuldade sentida pelo leitor comum em compreender a epopeia nacional, assim na atualidade foi considerado vantajoso proceder a uma paráfrase de cada estância, de modo a esclarecer e facilitar o acesso ao respetivo conteúdo num estilo deveras despretensioso e próximo do nível da oralidade de um falante de singela 
formação literária. Aparte esse aspeto, os responsáveis pela edição possibilitaram o diálogo entre o poema camoniano e nomes consagrados da lusofonia: se de um lado se perfilavam Manuel Alegre, Lídia Jorge, Fernando Campos, Mário de Carvalho, Jacinto Lucas Pires, Luísa Costa Gomes e Vasco Graça Moura; do outro, das literaturas atuais dos países lusófonos, contam-se José Eduardo Agualusa, Pepetela e Nélida Piñon. Cada um destes autores procedeu à composição de um conto de algum modo ligado ou inspirado num dos Cantos do poema, introduzindo-o assim e facilitando a sua compreensão de acordo com uma perspetiva hodierna, ao mesmo tempo que, desta feição, se aponta ao leitor a atualidade do poema camoniano numa realidade por demais afastada da sua génese. Traduz-se, deste modo e em simultâneo, o impacto da memória coletiva não só na sociedade portuguesa como na dos países lusófonos.

Ora, neste contexto, é de particular relevância a composição de Pepetela anteposta ao Canto V de Os Lusíadas. Não só por se tratar de um canto que ocupa um lugar de posição importante na geometria estrutural do poema, como Aníbal Pinto de Castro (2007, p.175) refere, quer por se posicionar precisamente no meio da obra, quer porque nele se situa um dos episódios de maior relevo, o do Adamastor, quer ainda porque nele se encerra o relato dos primeiros contactos dos navegadores com os povos africanos subsarianos.

Aliás, é no Canto V que Vasco da Gama faz o relato da sua viagem ao rei de Melinde. A fisionomia de novas terras, a configuração da costa africana, a observação de novas constelações, como o cruzeiro do sul, fenómenos inusitados como a tromba marítima e o fogo-de-Santelmo, fazem parte dessa grande aventura marítima, cujos perigos são acentuados pelos perigos expressos em episódios como o de Fernão Veloso, ameaçado pela hostilidade dos nativos, o do Adamastor, agente da fúria contra quem viola os seus domínios, e ainda a ameaça da doença e da morte provocadas pelo escorbuto.

O ponto alto do Canto é, pois, identificado com o episódio do Adamastor, pela sua originalidade, pela sua importância simbólica e até pela sua arquitetura. Dividido em três partes, na primeira (CAMÕES, V, 37-40) assiste-se à teofania de um gigante disforme, no meio do ambiente terrífico e grandioso de uma tempestade, envolto em nuvens de negra intimação, assumindo de imediato um tom intimidador 
contra quem perturba os seus domínios, sugerindo tal espetáculo a representação da experiência do terror, dos riscos de iminente aniquilação numa inflexão envolvente, terrificante e maravilhosa, que os mais ousados navegadores enfrentam ao atentaram contra os limites da humana sensatez. Pelo facto e como desenvolvimento natural desta primeira sequência, a segunda (CAMÕES, V, 41-48) encerra a enumeração das profecias de vingança do titã e dos riscos a enfrentar pelos heróis pósteros ao Gama (muito embora já passados no momento de composição do poema), tudo tratado como se de um oráculo se tratasse, de uma prolepse em termos diegéticos. A terceira e última parte do episódio (CAMÕES, V, 49-59), de teor intrinsecamente lírico, mais semelhante a uma écloga marinha, justifica a atitude e o comportamento de Adamastor, consubstanciada na história de um amor fracassado não correspondido pela ninfa Tétis, que se escande pela história do enamoramento, engano amoroso, separação, desengano e sonho frustrado de qualquer possibilidade de realização e feliz desenlace, para se encerrar com o despertar na triste realidade e o eterno lamento de desalento.

O relato continua, porém, acentuando o crescente desânimo sentido pelos navegadores pela falta de notícias da Índia, pelas experiências nada positivas dos contactos estabelecidos em Moçambique e Mombaça, apenas contrariadas pelo sucesso que a chegada a Melinde lhes proporciona, para depois se encerrar com o elogio do navegador à tenacidade dos portugueses, suscitando a admiração dos melindanos pela epopeia do povo português e pela própria viagem. Conclui-se o Canto V com a invetiva do poeta contra os contemporâneos que desprezam a poesia e a consequente possibilidade de cantar e louvar os heróis e os feitos dignos de memória, contrariamente ao que acontecia no passado com os gregos e romanos, amantes das letras.

No entanto, a preparar o clímax da narrativa da viagem, e depois de se apontarem as novidades observadas e experienciadas de novas constelações, do fogode-Santelmo e da tromba marítima, insere-se um breve mas significativo episódio que ocupa apenas um breve ciclo de estâncias (CAMÕES, V, 24-36), em que o protagonista é Fernão Veloso, curiosa figura de navegador, cuja psicologia remete para o português aventureiro da época, corajoso e simultaneamente fanfarrão, muito dado a experiências amorosas. É ele que volta a aparecer no Canto VI, incumbido de relatar o episódio cavaleiresco dos Doze de Inglaterra (CAMÕES, VI, 43-69), e no longo episódio da Ilha 
dos Amores, quando as ninfas se vislumbram e os navegadores iniciam, por sua sugestão, a perseguição de tão "estranha caça” (CAMÕES, IX, 69, 2).

No Canto V, porém, fica-lhe reservada, pois, a função de protagonista de um episódio inspirado em sugestões contidas colhidas na Ásia, de João de Barros, e na História do descobrimento e conquista da Índia pelos Portugueses, de Fernão Lopes de Castanheda (RODRIGUES, ${ }^{2} 1979,65-84$ ), que trata dos primeiros contactos com os povos nativos. Iniciado por um grupo de quatro estâncias (CAMÕES, V, 24-26) em que ainda é a voz do Gama que se afirma e refere o avistamento de terra nova, a descoberta de novos horizontes, a medição da altura do sol, a determinação geográfica do lugar, no hemisfério meridional e a surpresa do encontro com o primeiro dos indígenas. Centrando-se nesta nova personagem, que se ocupava na recolha de mel, embrenhado na montanha, as estâncias 27-30 constituem um segundo momento desta sequência. Tendo avistado de longe a chegada das caravelas, e acicatado pela curiosidade, avizinha-se da praia e aproxima-se dos navegadores. Apesar de logo ser considerado "mais selvagem do que o bruto Polifemo" (CAMÕES, V, 28, 4), é posto à prova perante amostras de ouro, prata e especiarias, na espectativa de se analisar a sua reação. Mais importância atribuiu, contudo, a contas de vidro, pequenos guizos e a um barrete vermelho, que, ufano, ostenta de regresso à aldeia.

O segundo momento desse episódio (CAMÕES, V, 30-33) incide sobre os acontecimentos do dia seguinte: o regresso do nativo acompanhado de toda a tribo, na espectativa de poderem ser contemplados com presentes semelhantes. É neste contexto que Fernão Veloso ousa acompanhá-los despreocupado até à aldeia, muito embora rápido regresse a correr pela praia, perseguido por toda a comitiva "bestial, bruta e malvada" (CAMÕES, V, 34, 4), que, agressiva, a todos atirava setas e pedras, deixando perceber claras intenções assassinas. Falhada a emboscada planeada de pronto o matarem, bem como quantos corressem a socorrê-lo, conseguira Fernão Veloso, célere, escapar-se-lhes, dando origem às escaramuças que ali logo se desenrolaram. Recolhido prestes no batel de Nicolau Coelho e em segurança, o desfecho do episódio (CAMÕES, V, 34-36) encerra as conclusões a que chegaram (a ignota distância da Índia, já que qualquer informação se revelara vã), o esclarecimento da situação vivida e o desfecho humorístico e de sabor anedótico, em que a bazófia do navegador é evidenciada. Como 
os amigos troçavam da rapidez do seu regresso, contraposta à confiança revelada aquando da sua partida para a aldeia, à sugestão de que o outeiro donde vinha era mais fácil de descer do que de subir, Fernão Veloso replica prontamente que a fuga apressada da sua vinda tivera lugar por se lembrar que todos estavam sem ele e sem a sua preciosa ajuda, assim enfraquecidos e desfalcados do seu valor de bravo combatente, nada havendo feito, pois, que revelasse aparente cobardia.

A ligeireza com que o episódio é apresentado, patenteada igualmente na resposta do protagonista, que se projeta como se da chave do episódio se tratasse; o tom humorístico resultante da prosápia e gabarolice do português; e ainda pelo facto de abrir caminho ao majestoso episódio do Adamastor, todos esses fatores contribuem para que a sua importância diegética se atenue e deste modo se trivialize a importância do relato do primeiro contacto com os povos africanos austrais.

Foi sobretudo neste breve passo que Pepetela se inspirou para compor o conto intitulado "Estranhos pássaros de asas abertas", anteposto a essa edição de $O s$ Lusíadas acima mencionada, de 2003, e depois inserido pelo autor angolano no volume Contos de Morte, de 2008, em quarto lugar, num corpus de cinco histórias dispersas, como na capa é expressamente declarado. Se bem que o episódio do Adamastor seja igualmente versado, passa a segundo plano e subordinado ao desenrolar da ação principal.

Não de forma muito diferente do que ocorre com a construção de alguns dos romances do autor, como Mayombe (1980), O Cão e os Caluandas (1985), Yaka (1985), Lueji (1990), A Geração da Utopia (1992), O Desejo de Kianda (1995) e A Gloriosa Família (1997), em que é possível delinear o uso da História e/ou da memória como leitmotiv recorrente para recontar a gesta da construção do percurso de um novo país como Angola e da construção da sua identidade a partir de um olhar interno, perspetiva já estudada por Lola Geraldes Xavier (2008, p.255-270), também Os Lusíadas aqui servem de ancoragem e ponto de partida para a recomposição dos contactos estabelecidos durante a epopeia dos descobrimentos, agora na mira pouco habitual dos povos africanos.

Como seria de esperar, mudada a perspetiva dos acontecimentos que marcam a diegese da epopeia, desta vez o narrador partilha a do povo da terra que 
assiste à chegada das caravelas, esses estranhos pássaros de asas abertas sobre a serena superfície das águas dos mares. As personagens são individualizadas (Namutu, Samutu, o filho Luimbi e o feiticeiro Manikawa); os traços de oralidade na escrita impõem-se a ponto de se tornarem sobremaneira mais visíveis no uso das preposições ("Contou no chefe, depois contou no povo..." p. 69), dos pronomes pessoais ("Três seres ... lhe arrastaram para a praia”, p. 71), e dos verbos (“[...] estão passar lá na baía.”, p. 71); e as manifestações da cultura popular cunham a mundivisão predominante fornecendo pistas para a explicação dos acontecimentos. Logo no arranque da narrativa se explicita que o feiticeiro havia tido uma visão nas labaredas do fogo e lido nos intestinos de um cabrito os factos que estravam prestes a ocorrer:

E Manikawa tinha contado, num sonho ele viu mesmo, iam chegar grandes pássaros de asas brancas e dentro deles saía gente estranha, como filhos-formiga brotando de ave morta. (PEPETELA, 2008, p.69)

A associação das caravelas a aves mortas, o pressentimento sentido, o coração apertado, a bater com força, tudo indicia a necessidade de precauções, de terem muito cuidado, de estarem prevenidos para o fluir dos acontecimentos. A diegese depois apoia-se no relato camoniano: Namutu apercebe-se da chegada daqueles estranhos seres sobre as águas da baía e fica inquieta porque Samutu fora recolher mel na floresta, na companhia do filho Luimbi, para sítios isolados. Mas o marido deixa entretanto a criança cansada na aldeia, para descanso da mulher, e volta à sua ocupação, quando é raptado por estranhos seres, lívidos como a morte, "de cheiro pestilento" e "aspecto desgrenhado de bandidos" (PEPETELA,2008,p.71). Mais parecem cazumbis, espíritos injustiçados vindos do além. A partir de então o discurso é moldado pela perceção dos factos proporcionado pela atenta observação do protagonista. O susto, a desorientação, o medo sentidos por Samutu acentua-se com os gritos ouvidos em língua estranha com que aqueles homens estranhos falavam entre si e que usavam para se dirigirem a ele. Arrastaram-no para diante de objetos desconhecidos e examinavam a sua reação:

Então, um de barbas lhe mostrou umas coisas que tinha na mão, pedras brilhando um pouco. E depois apresentou o que parecia pequenos frutos secos e depois pó bem cheiroso, que tapava o cheiro deles. (PEPETELA,2008,p.72) 
Como aquilo nada significasse para ele, ofereceram-lhe missangas de vidro colorido e um barrete vermelho. O ambiente crispado desanuviou-se. Todos riam e pareciam contentes. Em off, o narrador comenta:

Se Samutu percebesse a língua dos espíritos, teria entendido o que o chefe da barbas e que lhe mostrava as pedras brilhantes queria, saber se aqueles metais preciosos, ouro, prata, existiam ali, e saber também se ele conhecia especiarias do Oriente. (PEPETELA, 2008, p.74)

Os interesses dos “espíritos” eram, pois, de natureza económica. Por isso, no dia seguinte quando toda a tribo volta e traz mel, carne seca e cerveja de massango como oferendas, ficam felizes por receber em troca pano de barretes e mais missangas, e a oportunidade é aproveitada para se insistir e pôr à prova os conhecimentos dos indígenas acerca dos produtos que lhes interessavam: Os espíritos do mar mostraram de novo as pedras brilhantes e as especiarias, mas os da terra não reagiram a elas, não as conheciam (PEPETELA, 2008, p. 76)

Assim, se a primeira sequência trata da chegada dos pássaros de asas abertas sobre as águas da baía e dos primeiros contactos com Samutu; a segunda aborda o episódio do convívio e das trocas com a tribo; e a terceira foca verdadeiramente o episódio que Camões privilegia, as aventuras de Veloso.

Se afastaram levando as ofertas dos espíritos do mar. E um destes, o mais sorridente, avançou também, encorajado pelos da terra. Os outros espíritos chamaram o nome dele. Velôje, Velôje, mas não ligou, fez só um gesto para trás. Se afastavam da praia, os da terra todos satisfeitos, o espírito no meio deles, camarada, rindo e gritando sons só entendidos por ele. (PEPETELA, 2008, p.78)

Poeticamente explicada a situação criada com o roçar da túnica de Vénus, o certo é que o ambiente fica carregado de erotismo. Fernão Veloso tenta seduzir as mulheres que com ele caminham, primeiro a brincar, depois induzindo mesmo uma delas à violação.

As mulheres fugiram, rindo, esse espírito cheira mal, mas não pode ser um espírito porque nos abraçou com um corpo igual ao vosso, só que tem muitos pelos, sua muito e cheira como os mortos. (PEPETELA, 2008, p.78)

Os homens reagem: primeiro o marido dela puxa-o, de seguida Veloso puxa de uma 'faca grande' que traz à cintura; depois os restantes empunham porrinhos e 
azagaias. O ambiente fica tenso, Veloso descontrolado. Afogueado e demente, resta-lhe a fuga para junto dos seus.

Só que o seu mundo estava agora agitado pelo roçar da túnica de Vénus num espírito barbudo. Os da terra corriam atrás dele e os seus companheiros no batel e num outro que saiu de outro pássaro, apontaram às caras um paus que cuspiam fogo e dois da terra caíram feridos. (PEPETELA, 2008, p.79-80)

Curiosa é alusão aos paus que cospem fogo, que fazem ocorrer a partir deste momento sugestões colhidas na leitura de obras do contexto brasileiro. Neste caso específico, atualiza-se o modelo do Caramuru. Não é muito diferente o modo como esta ocorrência é tratada perante o modelo literário setecentista, já que Santa Rita Durão, no episódio a propósito de Diogo Álvares Correia, o "Filho do Trovão", trata o arcabuz de acordo com a mundivisão dos índios nativos e evidencia antes o fogo e o trovão nele gerados:

[...] Toma-a de mira Diogo e o ponto aguarda:

Dá-lhe um tiro e derriba-a co'a espingarda.

44. Estando a turba longe de cuidá-lo,

Fica o bárbaro ao golpe estremecido

E cai por terra no tremendo abalo

Da chama, do fracasso e do estampido:

Qual do hórrido trovão com raio e estalo

Algum junto aquém cai, fica aturdido,

Tal Gupeva ficou, crendo formada

No arcabuz de Diogo uma trovoada.

45. Toda em terra prostrada, exclama e grita

A turba rude em mísero desmaio,

E faz o horror que estúpida repita

Tupá, Caramuru, temendo um raio.

Pretendem ter por Deus, quando o permita,

$\mathrm{O}$ que estão vendo em pavoroso ensaio,

Entre horríveis trovões do márcio jogo,

Vomitar chamas e abrasar com fogo.

46. Desde esse dia, é fama que por nome

Do grão Caramuru foi celebrado

O forte Diogo; e que escutado dome

Este apelido o bárbaro espantado:

Indicava o Brasil no sobrenome,

Que era um dragão dos mares vomitado;

Nem doutra arte entre nós a antiga idade

Tem Jove, Apolo e Marte por deidade.” (DURÃO, II, 43-46) 
Naturalmente, considerando as respetivas diferenças em termos culturais e antropológicos, na medida em que, no caso dos índios, ao arcabuz se associa o poder da trovoada e do relâmpago, no caso dos africanos é o aspeto mais marcante, já que a um pau se associa e o resultado do tiro ser magia quase de todo inexplicável. As feridas causadas são uma "inesperada doença trazida pelos paus que cuspiam fogo e faziam estrondo" (PEPETELA,2008,p.80), e revelavam-se de tal forma graves que nem o Manikawa era capaz de as curar. Por isso, o feiticeiro admoestava os restantes elementos da tribo:

Eu bem dizia, cuidado, muito cuidado, ralhou Manikava. A estória podia ter tido outro fim, melhor ou pior, dizia a si própria Namutu, olhando melancolicamente as contas de vidro que obtivera dos espíritos. (Pepetela,2008,p.80)

As perplexidades assim expressas perante os resultados daquela aventura, realçadas pelos cuidados a tomar de futuro, bem podiam também recordar o desabafo de Cacambo n'O Uraguay, de Basílio da Gama, quando exclama, contra o domínio e o imperialismo da monarquia lusa no Brasil, em prol do primitivismo natural:

E o índio, um pouco pensativo, o braço

E a mão retira; e suspirando, disse:

Gentes da Europa, nunca vos trouxera

O mar, e o vento a nós. Ah! Não debalde

Estendeu entre nós a natureza

Todo esse plano espaço imenso de águas." (GAMA, II, 169-174)

Se essa acusação anticolonial é expressa num tom de desabafo e, simultaneamente, de consciente revolta, já n'O Canto do Piaga, de Gonçalves Dias, semelhante atitude é a resposta à pergunta "Esse monstro... - o que vem cá buscar?", aliás de maneira não muito diferente das interrogações que 'os estranhos pássaros de asas abertas' ali tinham vindo suscitar. Moldado segundo dos códigos do romantismo indianista, no Canto do Piaga enumeram-se, então, as desgraças que são a consequência da chegada do colonizador:

Não sabeis o que o monstro procura?

Não sabeis a que vem, o que quer?

Vem matar vossos bravos guerreiros,

Vem roubar-vos a filha, a mulher!

Vem trazer-vos crueza, impiedade -

Dons cruéis do cruel Anhangá;

Vem quebrar-vos a maça valente,

Profanar Manitôs, Maracás. 
Vem trazer-vos algemas pesadas,

Com que a tribu Tupi vai gemer;

Hão-de os velhos servirem de escravos

Mesmo o Piaga inda escravo há de ser?

Fugireis procurando um asilo,

Triste asilo por ínvio sertão;

Anhangá de prazer há de rir-se,

Vendo os vossos quão poucos serão.

Vossos Deuses, ó Piaga, conjura,

Susta as iras do fero Anhangá.

Manitôs já fugiram da Taba,

Ó desgraça! ó ruína!! ó Tupá!” (DIAS, 18-19)

Além da perda da liberdade, a chegada dessas estranhas gentes é sinónimo de morte dos guerreiros, de estupro das mulheres, de destruição e impiedade, de profanação de templos sagrados, escravidão, exílio e cativeiro. Até os deuses e os heróis nativos se revelam incapazes de atuar e serem bem-sucedidos. Quão próximo está, pois, O Canto do Piaga do conto de Pepetela! Nem a dimensão da religião indígena está ausente. O episódio camoniano do Adamastor acaba por inspirar uma linha secundária da ação na narrativa do autor angolano. Todavia, também os deuses mitológicos parecem igualmente colonizar aquelas paragens e reivindicar os territórios dos deuses nativos, que, obviamente, não se veem favoravelmente serem destituídos dos seus domínios. Afinal, a par do colonialismo que se verifica no plano dos humanos, também no plano do maravilhoso tal processo parece ter lugar:

Kianda ficou com raiva, ali, naquelas águas só Kianda podia agitar as profundezas e criar calemas. Quem era esse Neptuno para vir ali, no seu reino, provocar o caos? Fez recurso a Nzambi, o senhor de todos os deuses, o que bocejou depois de criar o mundo e os homens. Nzambi não gostou da intromissão de deuses estrangeiros no seu sítio. (PEPETELA, 2008, p.76-77)

Alguns detalhes, porém, distinguem as diferentes versões do relato mitológico. A paixão de Adamastor por Tétis agora acaba afinal por se consumar e, se bem que efemeramente, o prazer sentido valeu pela demora da espera. A metamorfose em rochedo ocorreu, mas os amantes assim ficaram abraçados para toda a eternidade naquele ato de amor que fez mudar a sorte de quantos por ali passavam. Já não se vingavam da ingerência de intrusos nos seus territórios, mas viam-nos passar a desafiar novos horizontes e outras divindades: 
Outro fim poderia também ter tido Adamastor, que, finalmente vendo Tétis deitada na praia em entrega, ao convite gulosamente acedeu e a ela se abraçou. E ao perceber que num rochedo ela se transfigurava, nele próprio sentiu também as carnes e os olhos virarem pedra. E passarem atrevidamente ao largo dele, imparáveis, os barcos daqueles espíritos indómitos que tiveram o valor de vergar as vontades de deuses. Mas que outros deuses e valores irremediavelmente ofenderam. (PEPETELA, 2008, p.80-81)

Por conseguinte, este é um exemplo produtivo de um ato de receção da obra camoniana nas novas literaturas lusófonas, que se vê enriquecida por sugestões porventura colhidas de leituras de obras inspiradas num processo de descolonização ocorrido mais de um século e meio antes. Os contextos diferem, as circunstâncias de composição também. Os autores vivem e refletem o mundo e as ideologias dominantes em cada época, mas o certo é que Camões e a obra camoniana, muito particularmente Os Lusíadas, constitui e continua a suscitar desafios a cada escritor, um estímulo à composição de novas obras, um ponto de partida para a inspiração poética, em suma, arvora-se em pilar de referência na vasta e crescente galáxia das literaturas que se exprimem em língua portuguesa.

\section{THE PLACE OF CAMÕES IN THE LITERARY GALAXY OF THE LUSOPHONE COUNTRIES}

ABSTRACT: Within the galaxy of the Portuguese speaking literatures, expression of the comunity of countries that use the Portuguese as the official language, Camões represents a reference to be followed and to be taken into account, not only within the Portuguese context, but also among the remaining nations. Therefore, and as an example, here is analysed the way how canto V of The Lusiads is taken as an inspiration source and a starting point by a contemporary Angolan writer, Pepetela, for the composition of the short-story entitled "Estranhos pássaros de asas abertas" / "Strange birds of open wings", afterwards included in the volume Contos de Morte / Tales of Death. Changes of perspective are pointed out, the evaluation of the native cultural context, underlining too the strangeness of those beings who came from remote places, more similar to spirits than to creatures of human condition. According to a post-modern approach, the dominant post-colonial angle fits, then, to the revisitation of the past, of the literary tradition and of the greatest epics of the Portuguese identity at the light of new parameters.

KeYwORDS: Luís de Camões, The Lusiads, Pepetela, Tales of Death, Post-Modernism, Post-Colonial Studies, Literary tradition.

\section{REFERÊNCIAS BIBLIOGRÁFICAS}


APPIGNANESI, Richard et al.. Introducing Post-Modernism. A Graphic Guide. Cambridge: Icon Books, 2005.

BUTLER, Christopher. Postmodernism. A very short introduction. Oxford: Oxford University Press, 2002.

CAMÕES, Luís de. Os Lusíadas. Leitura, Prefácio e notas de Álvaro Júlio da Costa Pimpão. Apresentação de Aníbal Pinto de Castro. Lisboa: Ministério da Educação / Instituto de Cultura Portuguesa, 1989.

CAMÕES, Luís de. Os Lusíadas. Em 10 volumes. Lisboa: Edição Expresso, 2003.

CASTRO, Aníbal Pinto de. O Episódio do Adamastor: Seu Lugar e Significação na Estrutura de Os Lusíadas. In CASTRO, Aníbal Pinto de. Páginas de um honesto estudo camoniano. Coimbra: CIEC, 2007, p. 175-190.

DIAS, António Gonçalves. Poesias. Rio de Janeiro: B. L. Garnier, ${ }^{6} 1877$.

DURÃO, Santa Rita. Caramuru. Poema épico do descobrimento da Bahia. São Paulo: Martins Fontes, 2001.

FERREIRA, António. Carta a Pero Vaz de Caminha. In FERREIRA, António. Poemas Lusitanos. Lisboa: Fundação Calouste Gulbenkian, 2000, p. 259-263.

FRANCISCO, Fabrice Teixeira. Entre a representação (pseudo-)histórica e a revisitação crítica dos alicerces do Cristianismo: 'Il Vangelo di Giuda' de Roberto Pazzi. Coimbra: FLUC, 2011.

GAMA, Basílio da. O Uraguay. In GAMA, Basílio da. Obras Poéticas. São Paulo: Editora da Universidade de São Paulo, 1996, p. 189-241.

HUTCHEON, Linda. Poética do Pós-modernismo. História-Teoria-Ficção. Rio de Janeiro: Imago Editora, 1991 (Trad. de A Poetics of postmodernism: history, theory, fiction. New York: Routledge, Chapman and Hall, 1988).

MARQUES, F. Costa. Nota Histórica e Literária. In FERREIRA, António, Poemas Lusitanos. Coimbra: Atlântida, ${ }^{2} 1973$, p. 6-46.

NAYAR, Pramod K.. Postcolonial Literature. An Introduction. New Delhi: Pearson / Longman, 2008.

PEPETELA. Contos de Morte. 5 Histórias dispersas. Lisboa: Edições Nelson de Matos, 2008.

RODRIGUES, José Maria. Camões e os historiadores Castanheda e João de Barros. In: RODRIGUES, José Maria. Fontes d'Os Lusíadas. Lisboa: Academia das Ciências de Lisboa, ${ }^{2} 1979$.

SEABRA, José Augusto. Uma língua. Sete espaços culturais. Camões, n. ${ }^{\circ}$ 1, 1998, p. 813.

VENTURA, José Manuel. Cartografias do Regresso: o intertexto camoniano em Vasco Graça Moura. Camões e os seus contemporâneos. Braga-Ponta Delgada-Coimbra: CIEC, 2012.

VENTURA, José Manuel. Camões e Vasco Graça Moura: tradição e metamorfose. Coimbra: Faculdade de Letras da Universidade de Coimbra, 2013. 
XAVIER, Lola Geraldes. Pepetela: entre a História e a Ficção. Limite, n. ${ }^{\circ}$ 2, 2008, p. 255-270. 